\title{
How to Distinguish Voluntary from Involuntary Unemployment: On the Relationship between the Willingness to Work and Unemployment-Induced Unhappiness
}

\author{
Adrian Chadi*
}

\section{INTRODUCTION}

Studies investigating the determinants of happiness show that unemployment causes high distress for most affected persons. Researchers conclude that the amount of this disutility demonstrates the involuntariness of unemployment. ${ }^{1}$ However, this conclusion is at odds with the opinions of many (labour market) economists. In fact, exponents from different fields of economics have conducted a heated debate about whether unemployment is predominantly a voluntary or involuntary phenomenon (see Worswick 1976). While several contributions explain how involuntary unemployment can occur (see Akerlof and Yellen 1986), in many labour market models, unemployment is primarily regarded as being a voluntary decision. $^{2}$

In addition to this theoretical aspect, there is also a political significance. If unemployment is primarily a voluntary phenomenon, labour market policies aimed at encouraging the unemployed to take up employment are logically consistent. On the contrary, for involuntarily unemployed people who are already willing to work, these policies would not only be doomed to failure, they might also be needlessly harmful. In this context, existing intrinsic motivation to take up employment could be crowded out by the implementation of such extrinsic incentives. In a nutshell, policies that are appropriate for one type of unemployed person can be disadvantageous for others. However, specific types of unemployment and corresponding frequencies are not usually part of labour market research. On the other hand, happiness researchers

* Faculty of Economics, Westphalian Wilhelms-University of Muenster, Universitaetsstr. 14-16, 48143 Münster, Germany, Tel.: +49 25183 28616, Email: Adrian.Chadi@ wiwi.uni-muenster.de

1. For a general survey on happiness research, see e.g. Frey and Stutzer (2002), Layard (2005), and Frey (2008).

2. For example, the basic idea of job search theory is that unemployed people compare alternatives, which are job offers and unemployment, and finally decide in favour of one or the other option. 
interpret the isolated disutility effect as evidence for involuntary unemployment, but they do not substantiate this argument by further investigating how this outcome may differ if additional information about the individual willingness to work is used. ${ }^{3}$

This paper seeks to bring together the potential of happiness research and the shortcomings associated with labour market research, so that certain labour market policies can be examined from a different perspective. Therefore, in order to analyse the relationship between the willingness to work and the loss of life satisfaction associated with unemployment, this paper uses German panel data from 1994 to 2007 as the basis for an econometric investigation. Along the way, it is possible to take a look at the prospects and actual impact of labour market policies that are based on the notion of primarily voluntary unemployment. Since the evaluation of recent labour market reforms in Germany has only just begun (see e.g. Wunsch and Lechner 2008), this paper aims to provide further politically significant insights into the effectiveness of such policy instruments.

Section II gives information on the data, some descriptive findings as well as methodological considerations in preparation for the econometric analysis. In Section III, the empirical results are presented, which are then (in Section IV) discussed generally and with regard to policy implications. Finally, some conclusions are drawn.

\section{DATA AND EMPIRICAL APPROACH}

This empirical analysis draws on data from the German Socio-Economic Panel (GSOEP). The annual panel survey is based on a wide variety of questions posed to individuals in selected German households. In order to analyse the willingness to work, the panel offers two appropriate variables, which are used here to explain life satisfaction. ${ }^{4}$ Firstly, the GSOEP asks non-employed persons about their future employment intentions ('Do you intend to engage in paid employment (again) in the future?'). Those individuals who are not employed, but intend to engage in employment, are asked whether or not they have actively searched for work. ${ }^{5}$ Until 1998, the question was: 'Have you searched actively for a new job within the last three months?' The period of

3. What has been examined so far is the relationship between unhappiness and the (in)voluntary nature with which unemployment is entered into. On this, see Kassenboehmer and Haisken-DeNew (2009).

4. GSOEP participants report their subjective well-being, based on the question 'How satisfied are you with your life, all things considered?' Responses range from 0 ('completely dissatisfied') to 10 ('completely satisfied').

5. Note that the groups of non-employed and unemployed persons are not identical. The unemployed are all part of the larger group of (simply) non-employed persons. Note also that unemployment is defined as people registered in the official unemployment register, so that unemployed in fact means registered as unemployed. 
three months was then reduced to four weeks in 1999. Hence, it is assumed that there is a structural break between 1998 and 1999, which implies the use of interaction variables, in order to correctly specify the econometric model. Because some of the relevant questions were part of the GSOEP questionnaire for a limited period only, the paper's sample involves the waves from 1994 to 2007. Furthermore, the analysis is restricted to persons of working age, that is, men and women aged 18 to 65 .

\section{Descriptive Analysis}

To illustrate the relationship between the voluntariness of unemployment and well-being, two diagrams are presented. Figure 1 is a graphical visualization of annual mean levels of life satisfaction calculated for 'all' participants, for 'employed' and for 'unemployed' people. The latter are subdivided (a) into those who are searching actively and those who are not, as well as (b) into three groups with different employment intentions. ${ }^{6}$ The diagrams reveal very substantial differences in well-being between employed and unemployed individuals. According to Oswald (1997), this should be referred to as the 'unhappiness gap of unemployment'. Regarding the relationship between unemployment-induced unhappiness and willingness to work, the initial descriptive findings speak for themselves. The unhappiness gap of unemployment widens for those individuals with the intention to work as well as for those actively seeking employment. Conversely, those who are not actively searching and those without employment intentions have, on average, a much higher level of individual well-being. The multiple regression analysis should demonstrate whether this seemingly clear relationship still holds, when the diverse factors influencing life satisfaction are controlled for.

Since the graphs of the unemployment subgroups in Figure 1 do not precisely follow the general pattern of the main graphs, another aspect must be considered. The atypical decline of the 'possibly' category (regarding the future employment question) could also have something to do with concurrent changes in the labour market. In 2004, the public dispute over the implementation of the so-called 'Hartz concept', which was based on the notion of activating the German unemployed, reached its peak. With respect to the econometric investigation, there is every reason to assume the occurrence of a structural break, particularly because the government's intention was, in fact, to implement systematic changes in the labour market.

6. The two middle options (concerning the future employment question) 'probably not' and 'probably' are merged into one called 'possibly', so that instead of four categories, there are 'no' (1), 'possibly' $(2 / 3)$ and 'yes' (4). 
Figure 1

Average life satisfaction of 18-65 year-old individuals in Germany (Source: GSOEP) Notes: The 'employed' group includes both full-time and regular part-time workers. Panel (a) subdivides 'unemployed' individuals into active and non-active searchers. Panel (b) shows three groups of unemployed with different employment intentions.
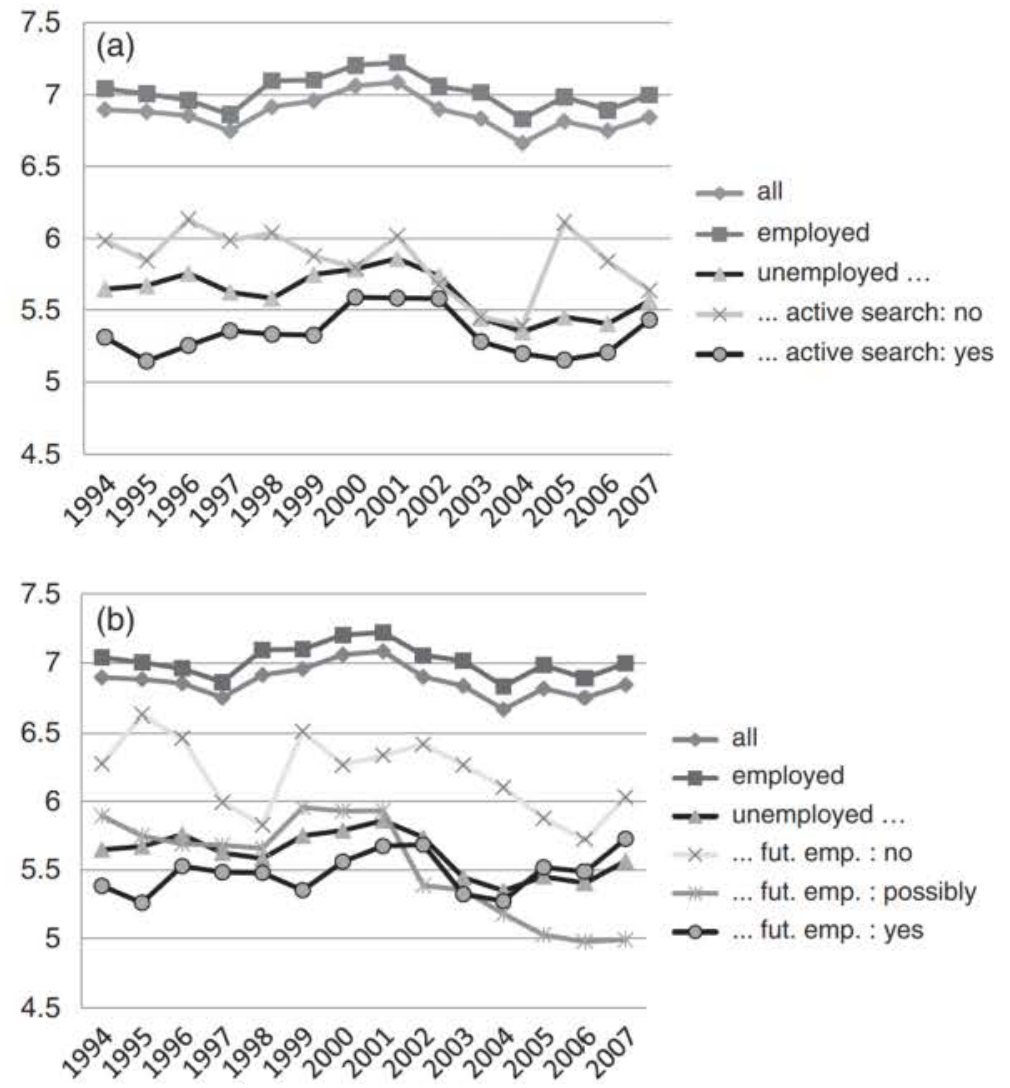

\section{Methodological Considerations}

Although empirical studies reveal that a considerable proportion of happiness is explained by changeable external factors, it is beyond dispute that well-being depends to a great extent on (given) personal traits (see Layard 2005). In their ground-breaking paper on the methodology of happiness research, Ferrer-iCarbonell and Frijters (2004) demonstrate that allowing for these fixed effects can produce substantially different results. Conversely, differentiating between ordinality and cardinality (with respect to the endogenous happiness variable) does not make much difference. They argue that it is far more important to allow for fixed personal characteristics than to consider the supposed problem of the endogenous (happiness) variable being non-cardinal. Therefore, the 
favoured method in this paper is OLS, with consideration of fixed effects, in particular, since many interaction terms are necessary in this analysis, and these outcomes can very easily be summed and interpreted after conducting OLS.

\section{RESULTS}

The OLS regression results of five differently specified fixed-effects models are shown in Table 1. Specification 0 is the simple basic model with one dummy variable for the state of registered unemployment. As in many other studies, there is a highly significant and sizeable negative impact on life satisfaction. This is the isolated disutility effect of unemployment, because the model includes control variables for the important influences on well-being (such as income, health and marital status), additionally, the influence of personal traits is reduced by allowing for fixed individual effects. In the following models, this negative effect of unemployment is divided by adding measures of the willingness to work.

Table 1

The Willingness to Work and the Effects of Unemployment on Life Satisfaction

\begin{tabular}{|c|c|c|c|c|c|}
\hline \multirow[b]{2}{*}{ Specification } & \multicolumn{5}{|c|}{ Fixed-Effects Ordinary Least Squares (OLS) } \\
\hline & (So) & (S1a) & $(S 1 b)$ & $(S 2 a)$ & $(S 2 b)$ \\
\hline Unemployment & $\begin{array}{c}-0.514^{* *} \\
(0.020)\end{array}$ & $\begin{array}{c}-0.296^{* * *} \\
(0.022)\end{array}$ & & $\begin{array}{c}-0.456^{* * *} \\
(0.021)\end{array}$ & \\
\hline Actively Looking: No & & $\begin{array}{r}-0.068^{*} \\
(0.026)\end{array}$ & $\begin{array}{r}-0.024 \\
(0.027)\end{array}$ & & \\
\hline Actively Looking: Yes & & $\begin{array}{c}-0.575^{* *} \\
(0.038)\end{array}$ & $\begin{array}{c}-0.451^{* *} \\
(0.046)\end{array}$ & & \\
\hline $\begin{array}{l}\text { Future Employment: } \\
\text { No (1.) }\end{array}$ & & & & $\begin{array}{c}0.021 \\
(0.052)\end{array}$ & $\begin{array}{r}-0.006 \\
(0.052)\end{array}$ \\
\hline Future Employment: & & & & $-0.106^{*}$ & $-0.113^{*}$ \\
\hline 'Possibly' (2.-3.) & & & & $(0.054)$ & $(0.055)$ \\
\hline Future Employment: & & & & $-0.221^{* *}$ & $-0.133^{*}$ \\
\hline Yes, Definitely (4.) & & & & $(0.053)$ & $(0.054)$ \\
\hline Interaction with Unemp & ment & & & & \\
\hline $\begin{array}{l}\text { Interaction Variable } 1 \\
\text { (IV1) }\end{array}$ & & & $\begin{array}{c}-0.287^{* * *} \\
(0.030)\end{array}$ & & $\begin{array}{c}-0.210^{* * *} \\
(0.036)\end{array}$ \\
\hline Interaction Variable 2 & & & $-0.389^{* *}$ & & $-0.395^{* *}$ \\
\hline (IV2) & & & $(0.041)$ & & $(0.036)$ \\
\hline $\begin{array}{l}\text { Interaction Variable } 3 \\
\text { (IV3) }\end{array}$ & & & & & $\begin{array}{c}-0.607^{* *} \\
(0.027)\end{array}$ \\
\hline Standard Controls & Yes & Yes & Yes & Yes & Yes \\
\hline Time-dummies & Yes & Yes & Yes & Yes & Yes \\
\hline Structural Break in 1999 & No & Yes & Yes & No & No \\
\hline (Adjusted) $\mathrm{R}^{2}$ & 0.122 & 0.125 & 0.125 & 0.122 & 0.123 \\
\hline
\end{tabular}

Source: GSOEP 1994-2007

Level of statistical significance: ${ }^{\circ} \mathrm{p}<0.1,{ }^{*} \mathrm{p}<0.05,{ }^{* *} \mathrm{p}<0.01$ 


\section{Actively Sought Work}

First of all, the information about job search activity is integrated into the model (Specifications 1a-b). By simply adding two dummy variables for the categories of 'looking actively' and 'not looking actively', while also integrating variables concerning the structural break in 1999, one major finding can already be identified. Active searchers, that is, individuals with a generally greater willingness to work, suffer substantially more from unemployment than those non-actively searching. Furthermore, the main effect of being unemployed is reduced from 0.514 to 0.296 , which indicates the prominent role of willingness to work in unemployment-induced unhappiness. The interrelation between this disutility and search activity is also shown in Specification $1 \mathrm{~b}$, which integrates interaction variables for unemployed persons, broken down into active and inactive searching (IV1, IV2).

\section{Intention Regarding Future Employment}

The second issue in the GSOEP questionnaire that is useful for this study is the question addressed to non-employed people, if they intend to engage in paid employment (again) in the future. Specification 2a contains three dummy variables, which are added to the basic model. ${ }^{7}$ The outcomes show that nonemployed persons, with an explicit intention to engage in employment, experience additional suffering. On the contrary, individuals without employment intentions suffer less in comparison to the general unemployment effect found in Specification 0. Consequently, the information on future employment intentions yields insights similar to the search-activity data. When dividing the unemployed into groups, by integrating interaction variables for unemployment and the intention categories, the results show an unambiguous relationship (Specification $2 b$ ). While individuals without any employment intentions do suffer, but to a lesser extent, unemployed people with increasing employment intentions experience increasing disutility effects.

\section{Levels of Willingness to Work}

In a third step, some additional interaction variables are introduced in the econometric model, which comprise the data about search activity and future employment intentions. Table 2 shows how information on these two variables

7. A regression with all four categories of the future employment question, that is 'no' (1), 'probably not' (2), 'probably' (3) and 'yes' (4), shows that the coefficients of the two middle categories are both weakly significant at about -0.1 , so that it seems reasonable to merge them into one 'possibly' category. 
Figure 2

Estimated Impact of Unemployment on Life Satisfaction in Germany (Source: GSOEP) Note: The panel shows the results of a fixed-effects OLS regression.

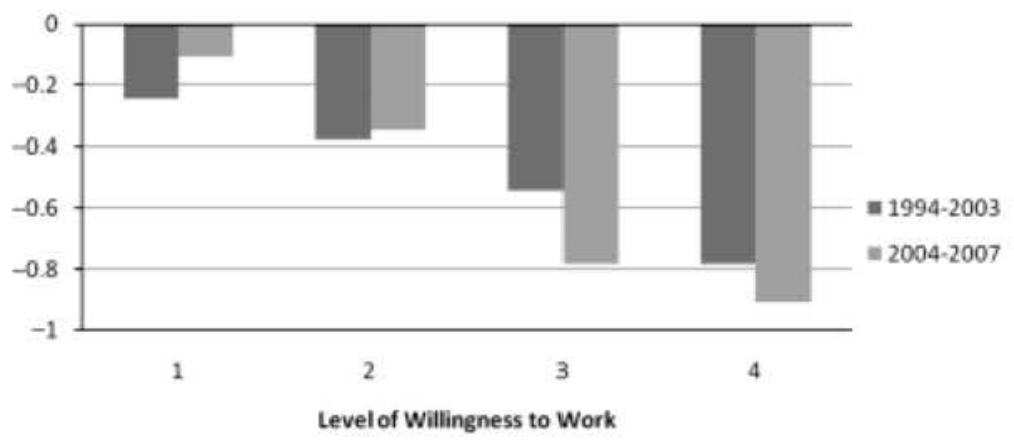

is merged into four levels of willingness to work. Furthermore, some additional interaction variables are generated in order to consider the potential structural break around 2004. However, due to the large set of coefficients, the effect for one group is not obvious anymore. Therefore, in order to obtain clarity, the regression outcomes are added and presented graphically in Figure 2. The strong connection between unemployment-induced disutility and willingness to work is clearly evident. All unemployed people suffer from their circumstances, but the differences are enormous. In particular, those with the highest level of willingness to work suffer on such a large scale, that it would be difficult to find determinants of happiness that could induce similar effects.

Nevertheless, there is an additional negative effect on the well-being of unemployed individuals who are actively looking for work, with respect to the structural break in 2004. In particular, those unemployed who are actively searching, but uncertain about the odds of obtaining future employment ('Level 3') experience an extraordinary additional negative effect. On the other hand, there is a considerable positive effect on unemployed individuals who reveal no willingness to work. This leads the disutility associated with unemployment, already relatively low for this group, to decline in such a way that it almost disappears.

\section{DISCUSSION}

The empirical investigation indicates that there is a close relationship between the willingness to work and unemployment-induced disutility. While those with the greatest willingness suffer most, unwilling individuals barely suffer from unemployment and can be called voluntarily unemployed. However, the majority in this sample should then be regarded as involuntarily unemployed. 
Table 2

Number of Observations Per Category

\begin{tabular}{|c|c|c|c|c|c|c|c|c|}
\hline \multicolumn{3}{|c|}{ Measures of Willingness to Work } & & & & & & \\
\hline Level & Active & Employment & \multicolumn{2}{|c|}{$1994-2007$} & \multicolumn{2}{|c|}{ a) $1994-2003$} & \multicolumn{2}{|c|}{ b) 2004-2007 } \\
\hline 1 & - & No & 2701 & $16.37 \%$ & 2050 & $18.09 \%$ & 651 & $12.60 \%$ \\
\hline 2 & No & Possibly/Yes & 4255 & $25.79 \%$ & 3015 & $26.61 \%$ & 1240 & $23.99 \%$ \\
\hline 3 & Yes & Possibly & 1715 & $10.39 \%$ & 1101 & $9.72 \%$ & 614 & $11.88 \%$ \\
\hline \multirow[t]{2}{*}{4} & Yes & Yes & 7828 & $47.45 \%$ & 5165 & $45.58 \%$ & 2663 & $51.53 \%$ \\
\hline & & & 16499 & $(100 \%)$ & 11331 & $(100 \%)$ & 5168 & $(100 \%)$ \\
\hline
\end{tabular}

As can be seen in Table 2, more than half the unemployed actively look for work, which inevitably means that they have an intention to engage in employment. On the other hand, about one sixth of the unemployed do not intend to engage.

\section{General Interpretation of the Results}

Unemployment impacts different people in different ways, so the findings of this paper suggest that it is important to consider the willingness to work in economic happiness research. For example, instead of translating the general unemployment effect into income, as Carroll (2007) did, distinguishing between different groups of unemployed would lead to quite dissimilar figures. Likewise, it should not be concluded from the general unemployment coefficient that the people without work are involuntarily unemployed, simply because of the large negative outcomes. In fact, there truly is something that can be called voluntary unemployment. There are a considerable number of unemployed people not intending to work (and therefore not searching for it) who experience a relatively small impact on their well-being as a result of individual unemployment. However, since most of these individuals are over 50 years of age, one might doubt that all of them are simply not interested in regular employment. ${ }^{8}$ Probably, some people are essentially unable to work or have lost confidence in returning to employment. On the contrary, there are surely senior citizens who prefer leisure time to work and, therefore, enjoy retiring earlier. Consequently, the overall negative coefficient for unemployed people with no intention to work could then be interpreted in such a way that this group consists of individuals with quite different backgrounds. Since some

8. The sample contains 2701 observations of unemployed individuals without any intention to work (Table 2). The average age is 55.6 years. 
older people might truly suffer from their situation, for whatever reason, the number of persons identified as voluntary unemployed (in a narrow sense) would be even smaller. In addition, however, there are other individuals, as part of the 'Level 2' group (see Table 2), who fall within a certain understanding of voluntary unemployment. These are people who have a general intention to work, but abstain from an active job search. Presumably, some of these individuals effectively choose to be out of work, since the average disutility effect caused by unemployment is much smaller than for the active work-seekers.

While the consideration of willingness to work provides some insight into voluntary unemployment, a look at the individuals at the other end of the scale reveals the true impact of unemployment on those most impacted. The general unemployment coefficients calculated by researchers have tended to lump all persons together. However, if those with no willingness to work are excluded, a much stronger disutility effect emerges. Therefore, the problem of unemployment is consistently underestimated. For example, the amount of money needed to compensate a willing person for being unemployed is higher than calculated in studies so far.

\section{Potential Impact of Labour Market Policies}

The results for the structural break in 2004 indicate diverse effects on unemployed individuals with regard to their willingness to work. While active job searchers suffer additionally, the unemployment-induced unhappiness of people with no intention to work actually decreases. At first glance, the political intentions associated with the labour market reforms seem to be contradicted by these figures. The involuntarily unemployed suffer more, while the voluntarily unemployed seem to be happier. In other words, those who are already willing to work experience additional pressure, whereas the intended targets of the policies do not.

A potential explanation for motivation effects working in the wrong direction is delivered by the theory of intrinsic motivation. According to Frey (1992), certain policy instruments can trigger unintended effects depending on how the applied measure is perceived in relation to self-determination and selfevaluation. To begin with, there are people who are intrinsically motivated to take up employment. In addition to social pressure, there is also an internal pressure to comply with the so-called social work norm, an individual's desire to find a job in order to make a living from work and to avoid welfare dependency (Stutzer and Lalive 2004). Following the distinction made by Lindenberg (2001), this is an obligation-based (as opposed to enjoymentbased) intrinsic motivation. This motivation, however, is presumably affected in an undesirable way by such labour market reforms, which unemployed 
individuals may consider to be controlling. Therefore, regarding the aspect of self-determination, people might feel forced to behave in a certain way, which generally reduces intrinsic motivation. In regard to self-evaluation, motivation could be increased by the acknowledgement of individual effort. However, when people find that their government assumes unwillingness, rather than taking note of the real level of motivation, the opposite effect seems likely. In the case of involuntarily unemployed people, even greater frustration and dissatisfaction could be the result. Therefore, extrinsic incentives to engage in employment, such as social benefit reductions, may have reduced some people's intrinsic motivation to engage in employment, while their unhappiness has increased. On the other hand, among people with less intrinsic motivation, such policies could have led to something that Lindbeck (1996, p. 624) calls 'unemployment cultures', when the resistance to living on benefits is not only reduced, but also a corresponding attitude is distributed among socially interacting individuals.

Certainly, there are so many aspects relevant to the situation of unemployed people that a clear-cut explanation is virtually impossible. For example, the changing conditions in the labour market could have led to a degree of uncertainty, which might explain the additional disutility effect on active jobseekers who are unsure about their future employment prospects. Another aspect has to be mentioned, namely the fluctuation effect following movements within different groups. If unemployed individuals change their attitude to work, as a consequence of the reforms, the calculated coefficients for the groups change as well. This fluctuation may explain why, since 2004, there are fewer people with no intention to work and relatively more unemployed who are willing to work (see Table 2). Furthermore, the flow of people into regular employment has to be considered. Given that the reforms increased the pressure on the unemployed to accept worse job offers as well, this flow should then attenuate the overall disutility for those who remain unemployed; since it can be assumed that, in particular, those who suffer most leave the ranks of the unemployed. Therefore, it is all the more remarkable that the results show increased unhappiness to be associated with involuntary unemployment. However, in the end, it is a political issue as to whether it is worthwhile forcing people into jobs that they would otherwise refuse.

\section{Policy Implications}

As a matter of fact, the German unemployment figures did fall in the aftermath of the labour market reforms, which advocates have attributed to the policies. However, contradictory to the basic idea of activating the unemployed, most individuals had already been active (while suffering very considerably 
from unemployment). Consequently, if these people have found a job, it can hardly be attributed to an activation effect. Policies aimed at eliminating voluntary joblessness would work for those who are indeed voluntarily unemployed. In fact, there is evidence that such individuals exist; yet the question remains as to whether policies can activate a significant number of them through extrinsic incentives. ${ }^{9}$

Another effect of the Hartz concept is likely to be relevant for the unemployment figures. The reforms and their impositions serve to exert pressure on the employee side, particularly with regard to wage bargaining, which could be one reason why wage growth in Germany has been relatively weak over the period in question. However, if it is assumed that there is a positive effect on labour demand, the question arises as to how many additional jobs are required to compensate for nationwide real wage reductions. Furthermore, if there is a small, but relevant and positive effect on the willingness to work caused by the reduction of social security, this has to be traded off against the potentially increasing uncertainties for the unemployed and also the people in regular employment. Finally, in investigating the consequences of unemployment, happiness research reveals another dilemma. If happiness is the ultimate goal, then lower unemployment-induced disutility should be positive. However, this has been associated with a lack of willingness to work and the voluntariness of unemployment. Alternatively, should the unemployed be as unhappy as possible in order to achieve lower unemployment? Surely, under certain circumstances unhappiness can be interpreted positively in economic terms, at least in the short run. ${ }^{10}$ The question then is how far decision-makers can go without being paternalistic.

In summary, there are various policy trade-offs, which can be identified by economists, but in most cases, cannot be solved. Furthermore, from the perspective of happiness research, labour market policies aimed at activating the unemployed do not work particularly well, which coincides with the findings of Wunsch and Lechner (2008). The results presented here suggest that 'activating' policies can lead to a certain decrease in unemployment figures, but in order to explain the substantial reduction of unemployment in Germany since 2005 , the economic recovery at that time surely has to be taken into account as well.

\section{CONCLUSION}

In this paper, it is shown that it is possible to distinguish between voluntary and involuntary unemployment and that the results of an empirical investigation

9. A closer look at the data supports these doubts, since there are hardly any cases in 2003 in which the unemployed with no intention to work took up employment in the following years.

10. Frey $(2008$, p. 5$)$ refers to 'liberal thinkers' who argue that being unhappy can have a stimulating effect on people's productivity. 
provide a basis for assessing certain labour market policies. Applying the happiness research approach, this study examines the relationship between the willingness to work and the disutility associated with unemployment. It is shown that there are unemployed individuals who do not make an effort to find a job and who barely suffer from being out of work. While these people can be regarded as voluntarily unemployed, at the other end of the scale, actively seeking unemployed people who are willing to work experience enormous negative effects on their well-being. This unemployment-induced unhappiness is consequently even stronger than determined by previous studies that have not considered the willingness-to-work factor.

Furthermore, the empirical results show that, since 2004, the majority of already active work-seekers suffer even more from unemployment, whereas the group of essentially voluntarily unemployed seems to enjoy a higher level of well-being than before. At first glance, this looks like an undesirable effect, which could be associated with the crowding-out of intrinsic motivation. Although there are many ways to interpret the empirical findings, the impact of social work norms and potential crowding-out effects in connection with these labour market policies are worthy of further research. In summary, the present study raises the question of whether the labour market reforms are the overriding factor capable of explaining the positive labour market trend in Germany since then. Moreover, this paper suggests that sound labour market policies should not focus only on the activation of the unemployed, in particular when the majority are already 'active'.

\section{REFERENCES}

Akerlof, George A. and Janet L. Yellen (1986). Efficiency Wage Models of the Labor Market. Cambridge: Cambridge University Press.

Carroll, Nick (2007). Unemployment and Psychological Well-being, Economic Record. 83: 287-302.

Ferrer-i-Carbonell, Ada and Paul Frijters (2004). How Important is Methodology for the Estimates of the Determinants of Happiness?, Economic Journal. 114: 641-659.

Frey, Bruno S. (1992). Tertium Datur: Pricing, Regulating and Intrinsic Motivation, Kyklos. 45: 161-184.

Frey, Bruno S. (2008). Happiness. A Revolution in Economics. Cambridge, MA. and London: The MIT Press.

Frey, Bruno S. and Alois Stutzer (2002). Happiness and Economics. How the Economy and Institutions Affect Well-being. Princeton (N. J.): Princeton University Press.

Kassenboehmer, Sonja C. and John P. Haisken-DeNew (2009). You're fired! The Causal Negative Effect of Entry Unemployment on Life Satisfaction, Economic Journal. 119: 448-462.

Layard, Richard (2005). Happiness. Lessons from a New Science. London: Allen Lane.

Lindbeck, Assar (1996). The West European Employment Problem, Review of World Economics. 132: 609-637.

Lindenberg, Siegwart (2001). Intrinsic Motivation in a New Light, Kyklos. 54: 317-342.

Oswald, Andrew J. (1997). Happiness and Economic Performance, Economic Journal. 107: 1815-1831. 
Stutzer, Alois and Rafael Lalive (2004). The Role of Social Work Norms in Job Searching and Subjective Well-Being, Journal of the European Economic Association. 2: 696-719.

Worswick, George D.N. (1976). The Concept and Measurement of Involuntary Unemployment. London: Allen \& Unwin.

Wunsch, Conny and Michael Lechner (2008). What Did All the Money Do? On the General Ineffectiveness of Recent West German Labour Market Programmes, Kyklos. 61: 134-174.

\section{SUMMARY}

Studies investigating the determinants of happiness show that unemployment causes high distress for most affected persons. Researchers conclude that the amount of this disutility demonstrates the involuntariness of unemployment. This paper applies the happiness research approach to German panel data in order to revive the underlying economic question of whether unemployment is voluntary or involuntary. Accordingly, the decline in life satisfaction associated with unemployment is related to the willingness to work. The results of the econometric investigation indicate a very strong connection between unemployment-induced disutility and willingness to work, so that it is possible to divide unemployed individuals into certain categories, according to the potential voluntariness of unemployment. While there is a minority which can truly be regarded as voluntarily unemployed, most unemployed people actively search for work and suffer far more from unemployment than indicated by previous happiness research studies. A subsequent discussion includes a critical juxtaposition of the findings with policies such as the recent German labour market reforms. 